\title{
Bilateral tension pneumothorax caused by an abrupt increase in airway pressure during cervical spine surgery in the prone position -A case report-
}

\author{
Jae-Young Lee, Joung Uk Kim, Eun-Hye An, Eun Song, and Yu Mi Lee \\ Department of Anesthesiology and Pain Medicine, Asan Medical Center, University of Ulsan College of Medicine, Seoul, Korea
}

Elevated peak inspiratory airway pressure (PIP) can occur during general anesthesia and is usually easily rectified. In rare circumstances it can lead to potentially fatal conditions such as tension pneumothorax. We report on a 77-year-old male patient admitted for a cervical laminoplasty. The preoperative chest radiograph showed normal findings and there was no medical history of allergy or underlying airway inflammation. Anesthesia induction and maintenance progressed uneventfully. However, 5 minutes after prophylactic antibiotic administration, PIP suddenly increased and blood pressure dropped. The operation was abandoned and the patient was moved to a supine position to perform chest radiography. Cardiac arrest occurred, and cardiopulmonary resuscitation was performed. The radiograph showed bilateral tension pneumothorax. Needle aspiration was immediately performed, and chest tubes were inserted. Ventilation rapidly improved and the vital signs normalized. The patient was discharged without sequelae on postoperative day 36. (Korean J Anesthesiol 2011; 60: 373-376)

Key Words: Anaphylaxis, Cardiac arrest, Peak inspiratory airway pressure, Tension pneumothorax.

An increase in the peak inspiratory airway pressure (PIP) during general anesthesia most often occurs when patients have underlying airway inflammation associated with conditions such as bronchial asthma, chronic obstructive pulmonary disease, or upper respiratory infection. Other causes of increased PIP include stimuli from laryngoscopy, improper positioning of an endotracheal tube, an endotracheal foreign body, and anaphylaxis from medication. Increased PIP often occurs during the induction and maintenance of anesthesia. The most common cause of increased PIP during anesthesia is anaphylaxis following administration of muscle relaxants or antibiotics, which accounts for up to $34 \%$ of cases [1]. Elevated PIP can usually be easily rectified using appropriate management. However, in rare cases elevated PIP can lead to

Received: September 30, 2010. Revised: 1st, November 11, 2010; 2nd, December 13, 2010. Accepted: December 15, 2010.

Corresponding author: Yu Mi Lee, M.D., Department of Anesthesiology and Pain Medicine, Asan Medical Center, University of Ulsan College of Medicine, 388-1, Pungnap-dong, Songpa-gu, Seoul 138-736, Korea. Tel: 82-2-3010-3868, Fax: 82-2-470-1363, E-mail: ylee@amc.seoul.kr (c) This is an open-access article distributed under the terms of the Creative Commons Attribution Non-Commercial License (http:// creativecommons.org/licenses/by-nc/3.0/), which permits unrestricted non-commercial use, distribution, and reproduction in any medium, provided the original work is properly cited. 
serious ventilation impairment or pulmonary barotraumas, and this can result in potentially fatal complications such as tension pneumothorax [2].

\section{Case Report}

A 77-year-old male presented to the department of neurosurgery with prolonged numbness and weakness in the limbs. Investigation revealed compression of the spinal cord by a herniated pulposus, and a cervical laminoplasty from the $3^{\text {rd }}$ to $6^{\text {th }}$ cervical vertebra was scheduled. The medical history included hypertension, diabetes, and a coronary artery bypass graft due to acute myocardial infarction 8 years prior. There was no history of allergy.

The patient was $158 \mathrm{~cm}$ tall, and weighed $60 \mathrm{~kg}$. Preoperative laboratory tests and chest radiography returned normal findings (Fig. 1A). Echocardiography showed hypokinesia of the basal inferior wall, but an ejection fraction of $63 \%$. Computed tomography of the coronary arteries showed that the graft vessels were satisfactorily patent. At the preanesthetic visit there were no complaints of dyspnea or chest discomfort.

Premedication was not used. Theatre monitoring included noninvasive blood pressure measurement, electrocardiography, pulse oximetry, and end-tidal carbon dioxide concentration $\left(\mathrm{E}_{\mathrm{T}} \mathrm{CO}_{2}\right)$ measurement. The vital signs before anesthesia were: a blood pressure (BP) of 161/78 mmHg, regular sinus rhythm with a heart rate (HR) of 50 beat/min and a peripheral oxygen saturation $\left(\mathrm{SpO}_{2}\right)$ of $99 \%$. Anesthesia was induced using lidocaine $40 \mathrm{mg}$, propofol $120 \mathrm{mg}$, and vecuronium $10 \mathrm{mg}$. After conducting mask ventilation for 3 minutes with $\mathrm{O}_{2} 4 \mathrm{~L} / \mathrm{min}$,
$\mathrm{N}_{2} \mathrm{O} 4 \mathrm{~L} / \mathrm{min}$, and sevoflurane 6 vol\%, the trachea was intubated with an 8.0-mm armored endotracheal tube. Anesthesia was maintained using $\mathrm{O}_{2} 1 \mathrm{~L} / \mathrm{min}$ and $\mathrm{N}_{2} \mathrm{O} 1 \mathrm{~L} / \mathrm{min}$, and sevoflurane $1.5-2.5$ vol\%. The vital signs remained stable after intubation. Mechanical ventilation was performed with minute ventilation of $5.5 \mathrm{~L} / \mathrm{min}, \mathrm{E}_{\mathrm{T}} \mathrm{CO}_{2}$ of $28-30 \mathrm{mmHg}$, and a PIP of $18 \mathrm{cmH}_{2} \mathrm{O}$. Subsequently, vecuronium $4 \mathrm{mg} / \mathrm{hr}$ was infused for continuous muscle relaxation. The patient was shifted to the prone position for the operation, and the PIP was $20 \mathrm{cmH}_{2} \mathrm{O}$ at that stage. Twenty minutes after anesthesia induction, cefuroxime sodium $1.5 \mathrm{~g}$ was administered as a prophylactic antibiotic without any previous allergic tests. Five minutes later, the PIP suddenly increased to $33 \mathrm{cmH}_{2} \mathrm{O}, \mathrm{E}_{\mathrm{T}} \mathrm{CO}_{2}$ slightly increased to 35 $\mathrm{mmHg}$, and $\mathrm{SpO}_{2}$ dropped to $94 \%$ and then recovered and was maintained at $97-100 \%$. The endotracheal tube was suctioned, but there was no evidence of a large amount of secretion. Ventilation impairment worsened, and PIP increased to 40 $\mathrm{cmH}_{2} \mathrm{O}$, BP dropped to $66 / 28 \mathrm{mmHg}$ and HR to 35 beats/min. We immediately converted to ambu bag manual ventilation, however severe resistance was experienced. Auscultation was difficult due to the surgical position and the operation field. Best possible use of a esophageal stethoscope revealed low breathing sounds. $\mathrm{N}_{2} \mathrm{O}$ administration was immediately ceased, and $100 \% \mathrm{O}_{2} 6 \mathrm{~L} / \mathrm{min}$ was administered. Suspecting that an anaphylactic reaction had occurred, hydrocortisone $100 \mathrm{mg}$ and vecuronium $3 \mathrm{mg}$ were injected for suspected bronchial spasm. However, ventilation did not improve. Atropine $0.5 \mathrm{mg}$ and epinephrine $10 \mu \mathrm{g}$ were injected, and a dopamine $10 \mu \mathrm{g} /$ $\mathrm{kg} / \mathrm{min}$ infusion was commenced to maintain BP. However, $\mathrm{BP}$ decreased to $56 / 22 \mathrm{mmHg}$ and HR to $30 \mathrm{beat} / \mathrm{min}$. Arterial
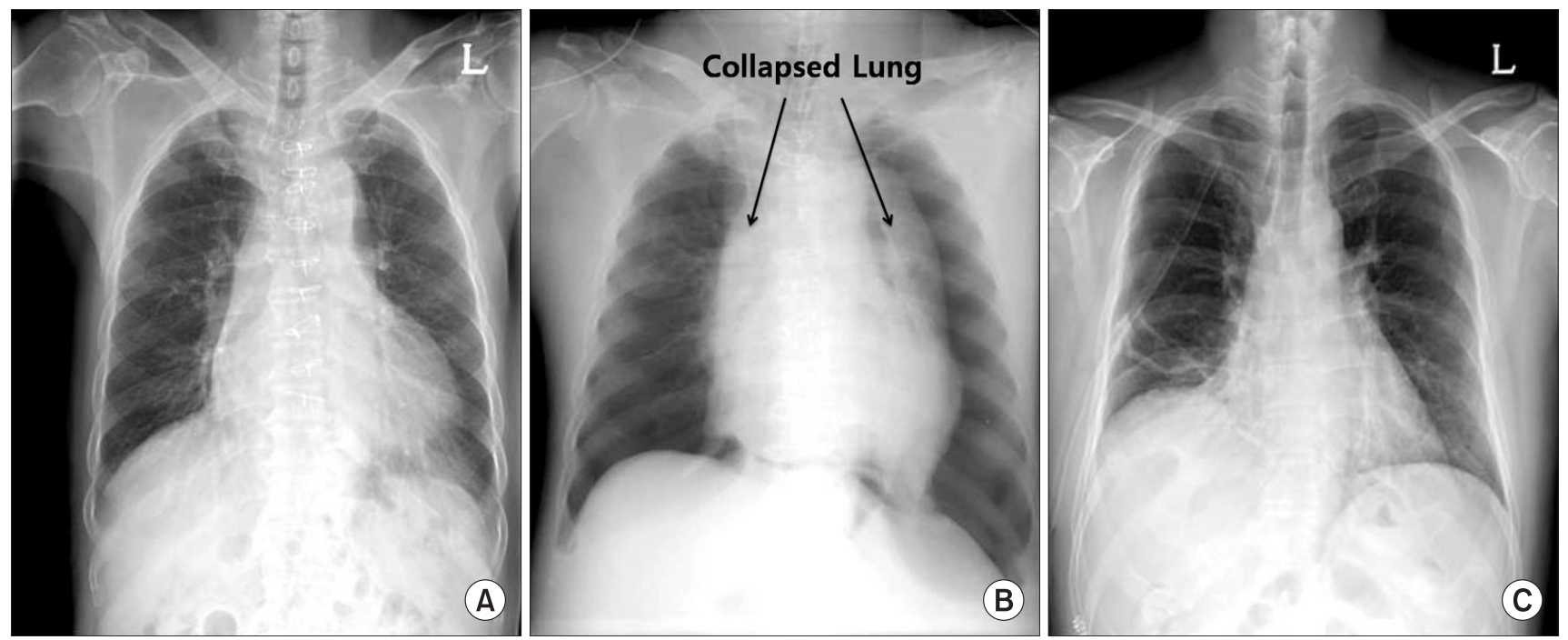

Fig. 1. Chest radiographs. (A) Preoperative chest radiograph. (B) Intraoperative chest radiograph. Note the bilateral tension pneumothorax. (C) Postoperative $13^{\text {th }}$ day chest radiograph. Note the resolved pneumothorax. 
Table 1. Serial Changes in Arterial Blood Gas Analysis Data

\begin{tabular}{|c|c|c|c|c|c|c|}
\hline & $\begin{array}{c}\text { After } \\
\text { induction }\end{array}$ & $\begin{array}{c}10 \text { min after } \\
\text { antibiotic adm. }\end{array}$ & $\begin{array}{c}\text { Cardiac } \\
\text { arrest }\end{array}$ & $\begin{array}{l}30 \text { min after chest } \\
\text { tube insertion }\end{array}$ & $\begin{array}{c}1 \mathrm{hr} \text { after ICU } \\
\text { arrival }\end{array}$ & $2^{\text {nd }}$ POD \\
\hline $\mathrm{pH}$ & 7.43 & 7.03 & 6.97 & 7.32 & 7.50 & 7.45 \\
\hline $\mathrm{PaCO}_{2}$ & 31 & 88 & $>115$ & 51 & 29 & 29.1 \\
\hline $\mathrm{PaO}_{2}$ & 180 & 345 & 30 & 399 & 90 & 163.7 \\
\hline $\mathrm{BE}$ & -3.3 & -7.9 & UC & 0.1 & -0.1 & -3.5 \\
\hline $\mathrm{HCO}_{3}^{-}$ & 20.6 & 23.2 & UC & 26.0 & 23.0 & 20.7 \\
\hline $\mathrm{SaO}_{2}$ & 100 & 100 & UC & 100 & 98 & 99.6 \\
\hline $\mathrm{FiO}_{2}$ & 0.5 & 1.0 & 1.0 & 1.0 & 0.5 & 0.36 \\
\hline
\end{tabular}

pH: hydrogen ion concentration, $\mathrm{PaCO}_{2}$ : partial pressure of arterial carbon dioxide, $\mathrm{PaO}_{2}$ : partial pressure of arterial oxygen, $\mathrm{BE}$ : base excess, $\mathrm{HCO}_{3}{ }^{-}$: bicarbonate, $\mathrm{SaO}_{2}$ : oxygen saturation, $\mathrm{FiO}_{2}$ : fraction of inspired oxygen, UC: uncheckable, min: minute, hr: hour, ins.: insertion, ICU: intensive care unit, adm: administration, POD: postoperative day.

blood gas analysis (ABGA) showed a pH of 7.03, $\mathrm{PaCO}_{2}$ of $88 \mathrm{mmHg}, \mathrm{PaO}_{2}$ of $345 \mathrm{mmHg}$, and $\mathrm{SaO}_{2}$ of $100 \%$ (Table 1). Epinephrine $30 \mu \mathrm{g}$ was administered under continuous infusion at $0.05 \mu \mathrm{g} / \mathrm{kg} / \mathrm{min}$. Chest radiography was then considered essential to determine whether there was a mechanical problem or pulmonary complication. However, this was difficult due to the iron frame of the operating table. Moreover, the patient was undergoing cervical spine surgery in a fixed prone position, and if cardiac arrest eventuated, it would have been very difficult to perform cardiopulmonary resuscitation (CPR). Therefore, the surgery was abandoned and the surgical wound promptly closed. Ventilation did not improve and breathing was scarcely heard during wound closure. The patient was placed in the supine position and chest radiography performed. Cardiac arrest occurred. Atropine $1 \mathrm{mg}$ and epinephrine $1 \mathrm{mg}$ were immediately injected twice while chest compression was conducted for 10 minutes. Subsequently, BP increased to 110/43 $\mathrm{mmHg}$ and $\mathrm{HR}$ to 48 beat $/ \mathrm{min}$. $\mathrm{SpO}_{2}$ decreased to $70 \%$ and ABGA showed a $\mathrm{pH}$ of $6.97, \mathrm{PaCO}_{2}$ of $115 \mathrm{mmHg}$, and $\mathrm{PaO}_{2}$ of 30 $\mathrm{mmHg}$. The chest radiograph revealed tension pneumothorax in both lungs (Fig. 1B). Needle aspiration was immediately performed, followed by the insertion of chest tubes into the thoracic cavity. Following tube insertion, ventilation improved and PIP decreased to $28 \mathrm{cmH}_{2} \mathrm{O}$. ABGA showed a $\mathrm{pH}$ of 7.32, $\mathrm{PaCO}_{2}$ of $51 \mathrm{mmHg}, \mathrm{PaO}_{2}$ of $399 \mathrm{mmHg}$, and $\mathrm{SaO}_{2}$ of $100 \%$. The vital signs normalized, BP was 135/54 mmHg, and HR was 52 beat $/ \mathrm{min}$. The patient was transferred to the intensive care unit with intubation.

On the $2^{\text {nd }}$ postoperative day (POD), extubation was performed without complication. On the $13^{\text {th }}$ POD, follow-up chest radiography showed no abnormalities except atelectasis in both lungs (Fig. 1C). The chest tube was removed and the patient was discharged without sequelae on the $36^{\text {th }}$ POD.

\section{Discussion}

The present case is an example of allergic reaction-induced bronchial spasm followed by a sudden increase in PIP and ventilation impairment during maintenance of general anesthesia. This series of events caused tension pneumothorax which ultimately required CPR.

Elevated PIP is common during anesthesia and is generally corrected without serious complications. Westhorpe et al. [1] reported that PIP often increases by $56-75 \%$ during induction and maintenance of anesthesia, and Cheney et al. [3] reported increases of $25-43 \%$ during anesthesia maintenance. The causes of increased PIP during general anesthesia include stimulation from intubation, a large volume of bronchial secretion, sudden inhalation of highly concentrated anesthetic, underlying respiratory disease such as chronic bronchitis or asthma, and allergic reactions to anesthetics and antibiotics [4].

The most common clinical symptom of high airway pressure is hypercapnia, making ventilation of the lungs difficult and leading to considerable $\mathrm{CO}_{2}$ emission impairment from the alveoli. The second most common symptom is hypoxia. In the case of oxygen, this gas moves into the blood through the alveoli unilaterally from the outside. Therefore, if oxygen is forced under high pressure from the outside, it can move into the alveoli, maintaining the $\mathrm{SaO}_{2}$ level. However, when there are lesions causing an alveolar ventilation/perfusion mismatch or perfusion defects in the pulmonary capillaries due to a decrease in BP, hypoxia can occur [2].

In the present case, it appeared that complications developed following the administration of the prophylactic antibiotic, and PIP increased due to the increase in airway resistance. Furthermore, due to the ventilation impairment, $\mathrm{PaCO}_{2}$ increased and $\mathrm{SpO}_{2}$ temporarily decreased to $94 \%$ at the beginning of the PIP increase. After supplying $100 \% \mathrm{O}_{2}$ at a high flow rate, $\mathrm{SpO}_{2}$ was maintained at $97-100 \%$.

Pneumothorax can develop as a result of increased PIP [2]. The endotracheal pressure causing pneumothorax has yet to be identified, but it is known to be associated with increased barotrauma as the peak airway pressure increases [5]. The clinical signs and symptoms of pneumothorax are hypoxia 
and hypercapnia due to a decrease in lung volume caused by the sudden increase in intrathoracic pressure. When the volume of the pneumothorax is large enough to develop tension pneumothorax, as in our case, cardiac output decreases because venous circulation is blocked due to compression of the vena cava, atrium, and large veins by shifting of the mediastinum. This can eventually cause hypotension leading to circulatory collapse [6].

Lobera et al. [7] reported that anaphylaxis during anesthesia was due to antibiotics in $44 \%$ of cases and muscle relaxants in $37 \%$ of cases. In the present patient, although allergic test was not performed prior to administer cefuroxime sodium using in our case by the policy of our institution and neither did it after the event to confirm the allergic reaction considering his general condition, antibiotic-induced anaphylaxis appeared to be the initiating event. That anaphylaxis resulted in an increase in PIP, which in turn caused positive pressure ventilation which caused development of pneumothorax, and this eventually developed into tension pneumothorax.

Upon suspicion of a bronchial spasm, clinicians should increase the depth of anesthesia using anesthetic agents and muscle relaxants, and also administer a bronchodilator such as a $\beta$-adrenergic agent. Aminophylline can also be administered to improve ventilation [2]. Moreover, although the mechanism is not clear, an injection of hydrocortisone can be effective, but this takes hours to have a clinical effect [8]. $\mathrm{MgSO}_{4}$ is effective for patients who experience a bronchial spasm [9]. In patients with respiratory diseases, a lack of response to such treatments should result in immediate transfer to an intensive care unit to establish ventilation. If pneumothorax occurs due to complications associated with a bronchial spasm, $\mathrm{N}_{2} \mathrm{O}$ administration should be immediately ceased and $100 \%$ oxygen should be given. A large-bore needle should also be inserted into the $2^{\text {nd }}$ intercostal space for aspiration of air from the thorax. Finally, water-sealed drainage via chest tubes should be instigated. In cases of cardiovascular collapse due to tension pneumothorax, BP should be maintained using vasoconstrictors and inotropics.

The present report describes a case of a sudden increase in
PIP after antibiotic administration which then developed to the potentially fatal condition of tension pneumothorax. This occurred in a patient with no history of allergy, no underlying respiratory inflammation and no abnormal findings during anesthesia induction. The planned surgery, like this case in the fixed prone position, was abandoned in order to obtain chest radiographs and to prepare for life-saving CPR if cardiac arrest occurred, which did indeed eventuate. In the present patient, this course of action resulted in recovery with no obvious sequelae. This case highlights that potentially fatal tension pneumothorax can develop in patients who may be considered at low risk of such a complication, and that a timely decision to abandon planned surgery, especially prompt CPR is not available, may be crucial in avoiding further serious complications or death.

\section{References}

1. Westhorpe RN, Ludbrook GL, Helps SC. Crisis management during anaesthesia: bronchospasm. Qual Saf Health Care 2005; 14: e7.

2. Oh SC, Son YS, Nam SW, Yoon KJ. Bronchospasm during the Maintenance of General Anesthesia. Korean J Anesthesiol 2005; 49: 532-7.

3. Cheney FW, Posner KL, Caplan RA. Adverse respiratory events infrequently leading to malpractice suits. A closed claims analysis. Anesthesiology 1991; 75: 932-9.

4. Kim SW, Kim JG, Lee JS, Kwon BY. Acute attack of asthma and pulmonary collapse after tracheal intubation. Korean J Anesthesiol 1995; 28: 722-7.

5. Haake R, Schlichtig R, Ulstad DR, Henschen RR. Barotrauma. Pathophysiology, risk factors, and prevention. Chest 1987; 91: 608-13.

6. Moon JE, Ahn HJ, Kim JA. Bilateral tension pneumothorax and bronchospasm in the patient with recent history of croup: A case report. Korean J Anesthesiol 2007; 52: 724-7.

7. Lobera T, Audicana MT, Pozo MD, Blasco A, Fernández E, Cañada $\mathrm{P}$, et al. Study of hypersensitivity reactions and anaphylaxis during anesthesia in Spain. J Investig Allergol Clin Immunol 2008; 18: 350-6.

8. Barnes PJ. Mechanisms of action of glucocorticoids in asthma. Am J Respir Crit Care Med 1996; 154: S21-6; discussion S6-7.

9. Skobeloff EM, Spivey WH, McNamara RM, Greenspon L. Intravenous magnesium sulfate for the treatment of acute asthma in the emergency department. JAMA 1989; 262: 1210-3. 